\title{
Single and double aging treatments on Mg97Zn1Y2 alloy
}

\author{
*Di-qing Wan, Ying-lin Hu, Hou-bin Wang, Shu-ting Ye \\ School of Material Science and Engineering, East China Jiaotong University, Nanchang 330013, China
}

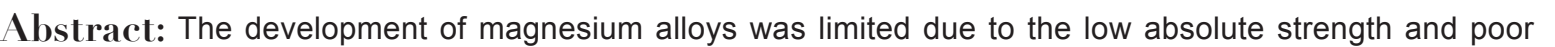

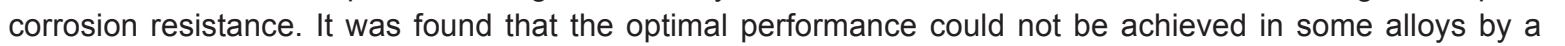

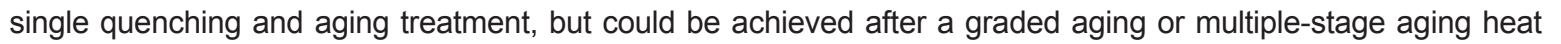

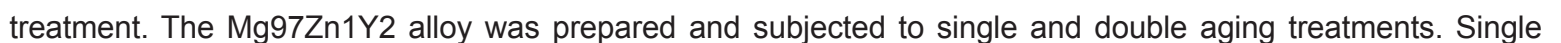
aging was carried out at $250^{\circ} \mathrm{C}$ for 6 to $15 \mathrm{~h}$. For double aging, the first step was performed the same as the (1)

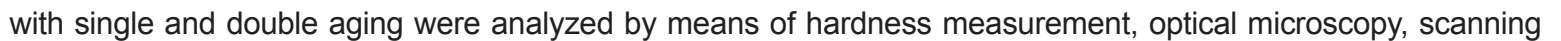

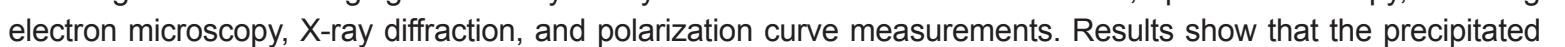

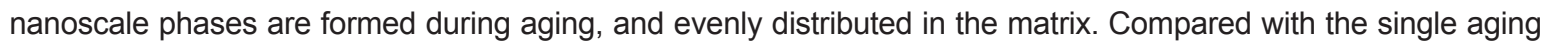

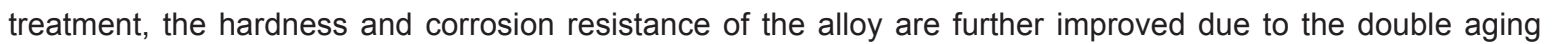

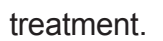

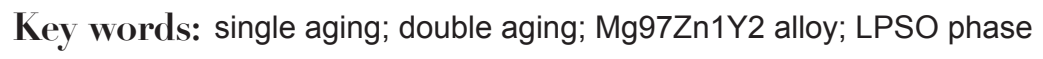

CLC numbers: TG146.22

Document code: $\mathrm{A}$

Article ID: 1672-6421(2019)01-046-07

$\square$

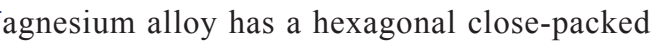

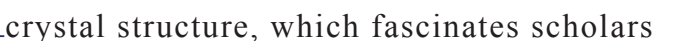

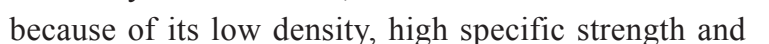
elastic modulus, and high recycling efficiency

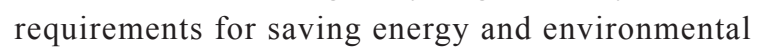

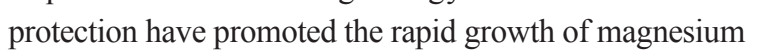

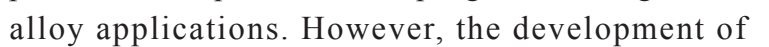

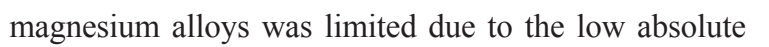

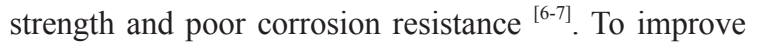

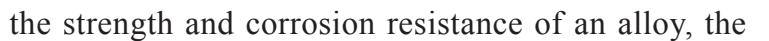

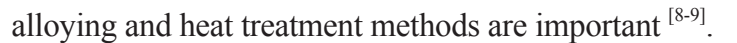

ए

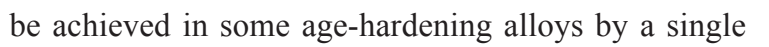

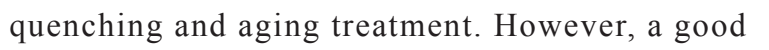

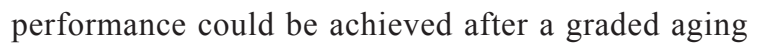

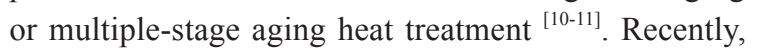

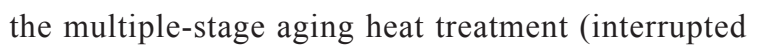

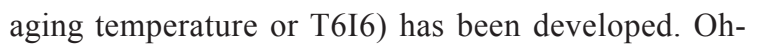

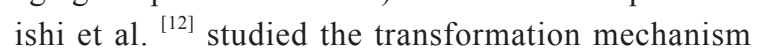

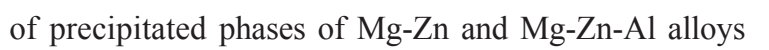

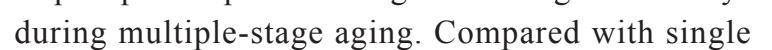

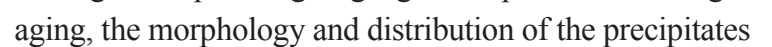

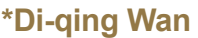

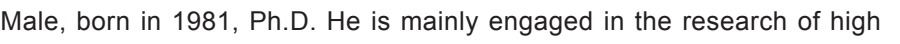

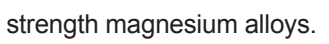

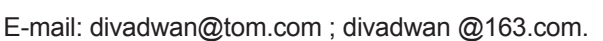

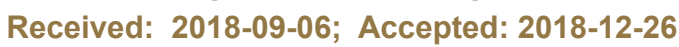

changed significantly after double aging. Graded aging

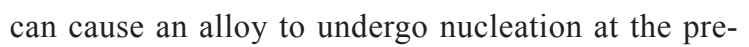

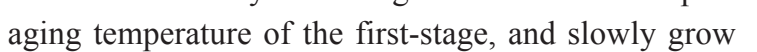

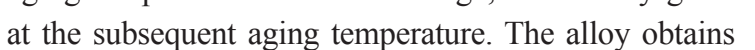

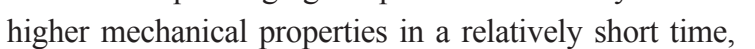

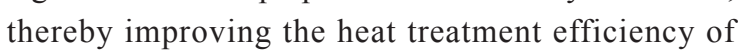
ए।

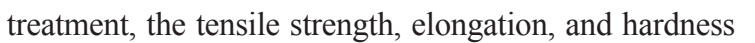

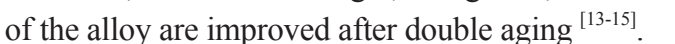

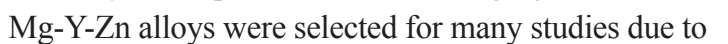

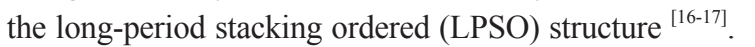

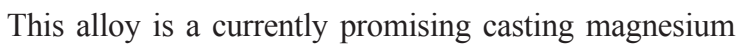

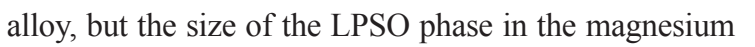

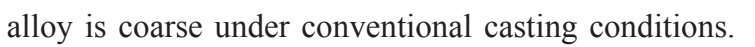

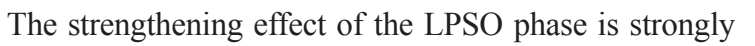

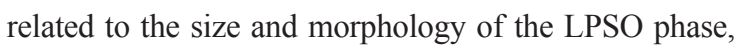

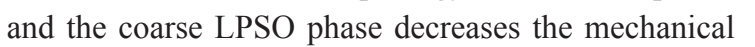

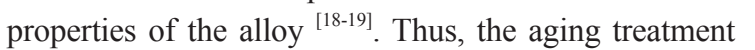

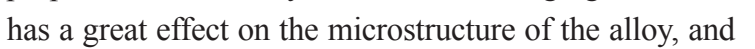

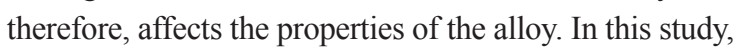

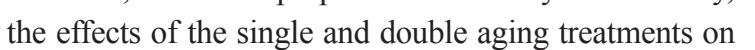

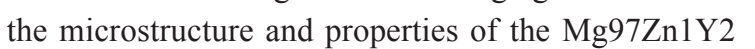

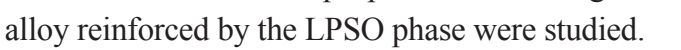

\section{Experimental procedure}

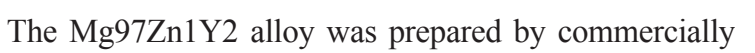

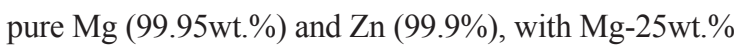




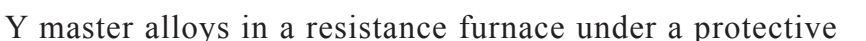

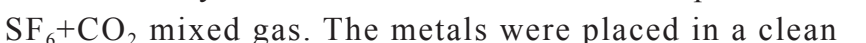

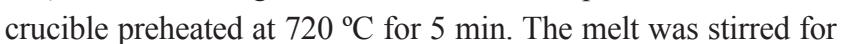

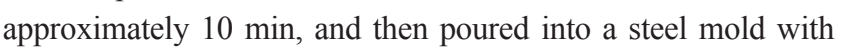

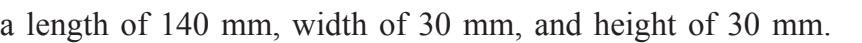

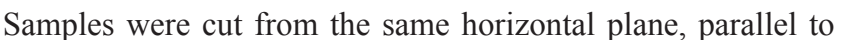

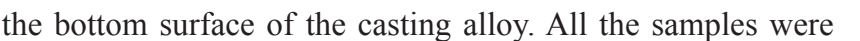

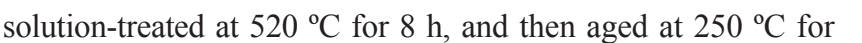

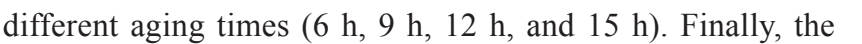

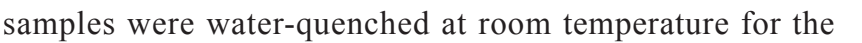

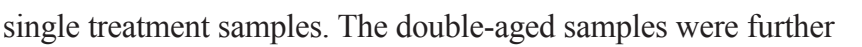

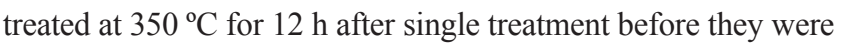

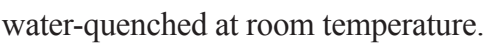

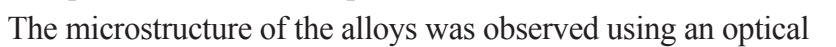

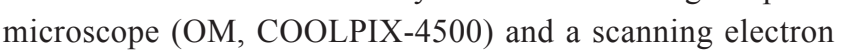

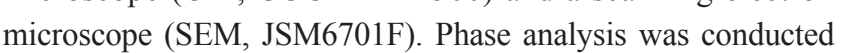

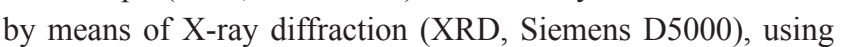
monochromatic $\mathrm{Cu}-\mathrm{K} \alpha$ radiation with $0.05^{\circ}$ step length. The

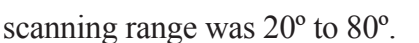

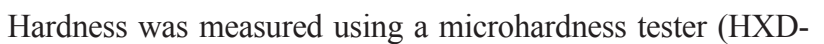

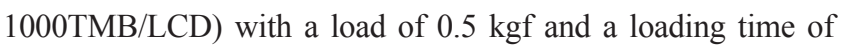

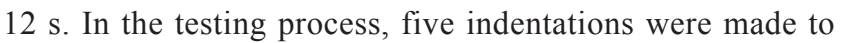

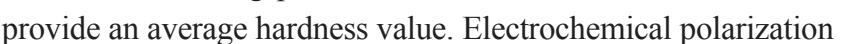

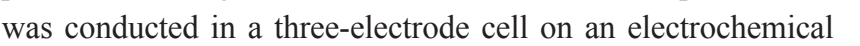

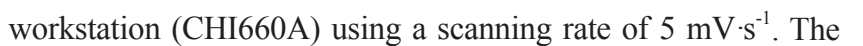

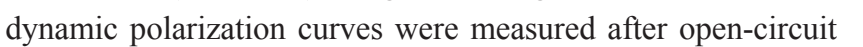

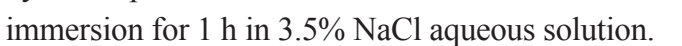

\section{Results and discussion}

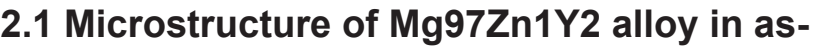

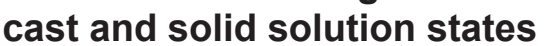

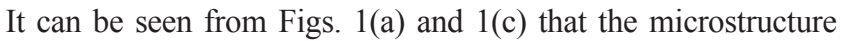
of Mg97Zn1Y2 alloy consists of the dendritic $\alpha-\mathrm{Mg}$ matrix and

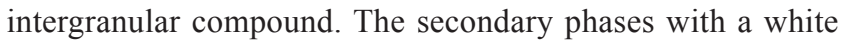

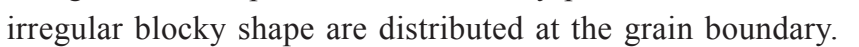

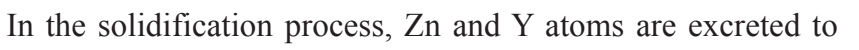
யா

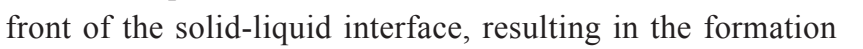

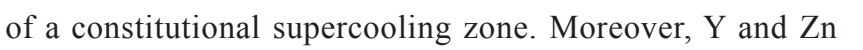

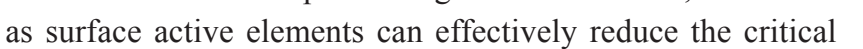
nucleation radius. So, the $\alpha-\mathrm{Mg}$ phase is firstly crystallized and then the secondary phase is formed during solidification.

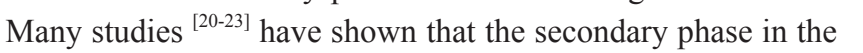

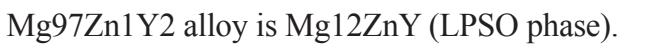

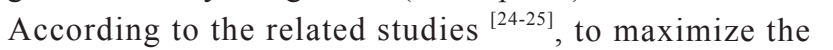

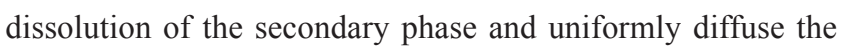
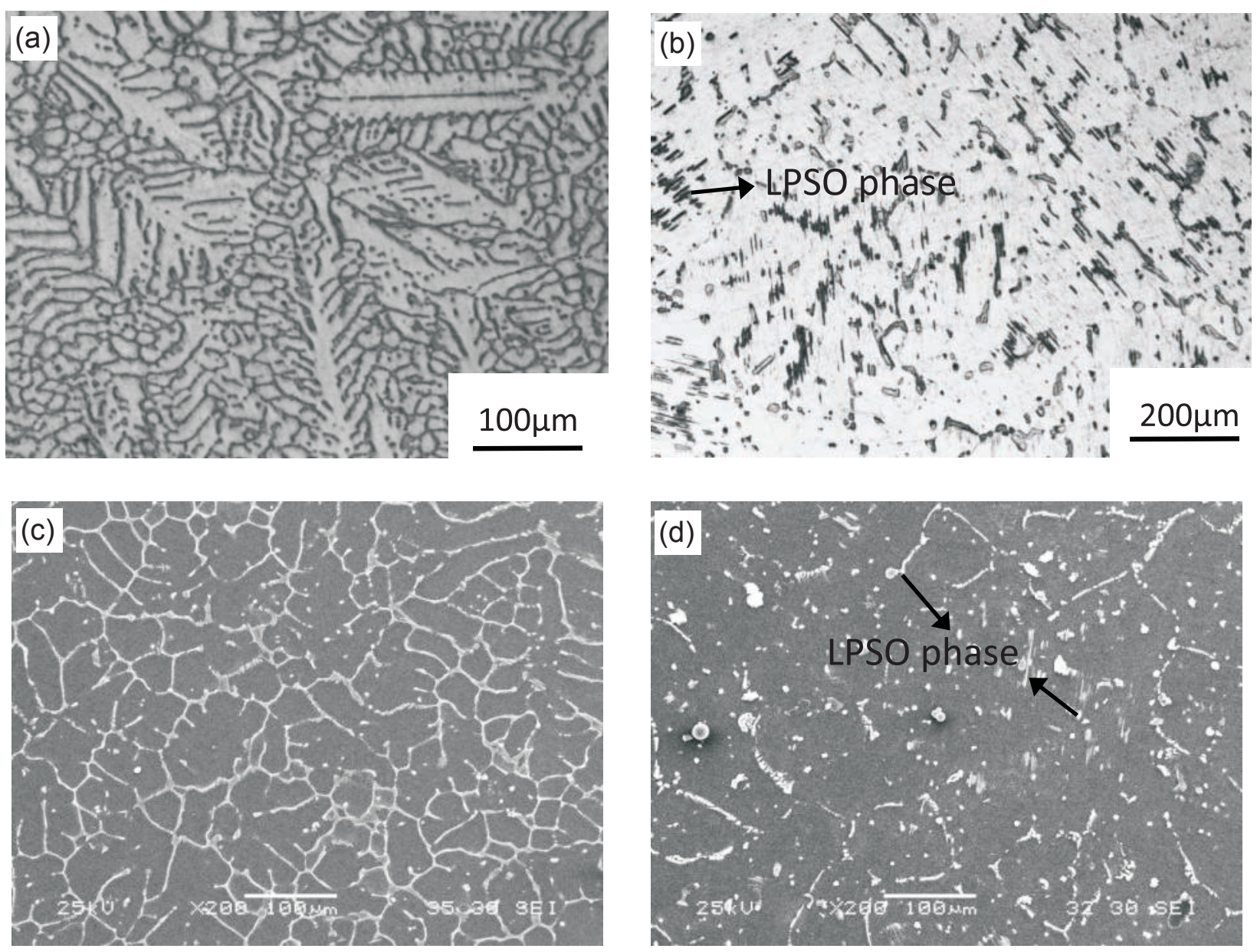

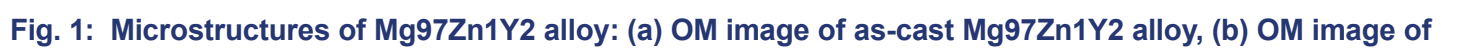

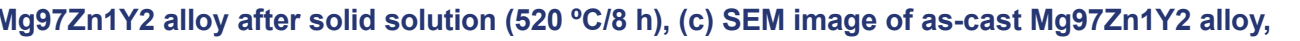

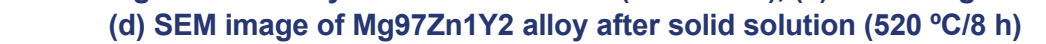




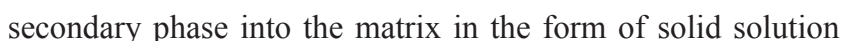

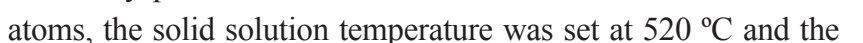

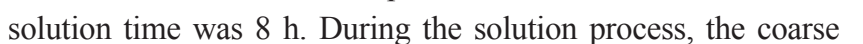

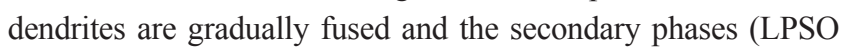

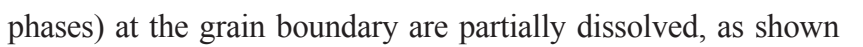

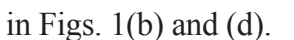

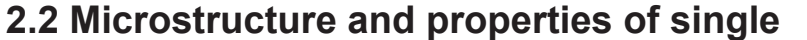

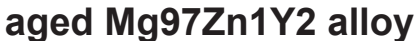

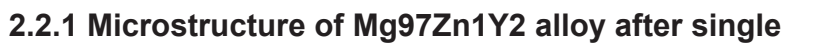

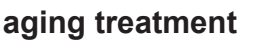

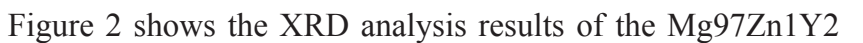

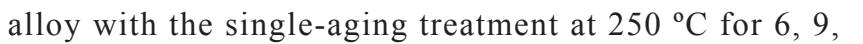

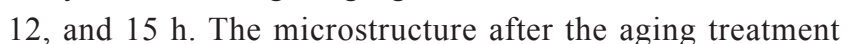
is composed of $\alpha-\mathrm{Mg}$ matrix and $\mathrm{Mg} 12 \mathrm{ZnY}$ phase. With

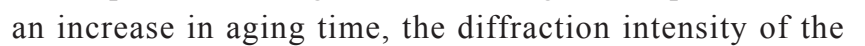

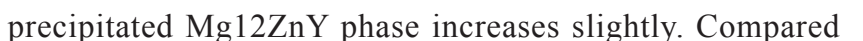

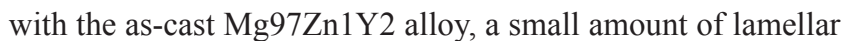

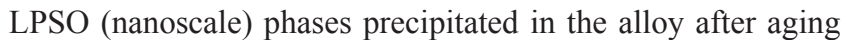

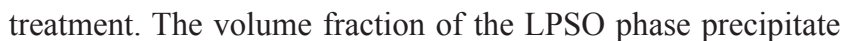

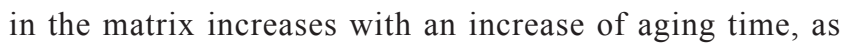
एमापाणाणा

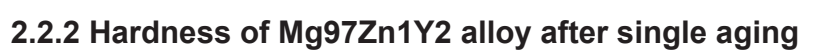

$\square\left[\begin{array}{ll}\square \square \square \square \\ \square \square \square\end{array}\right.$

As shown in Fig. 4, the hardness of the alloy firstly increases
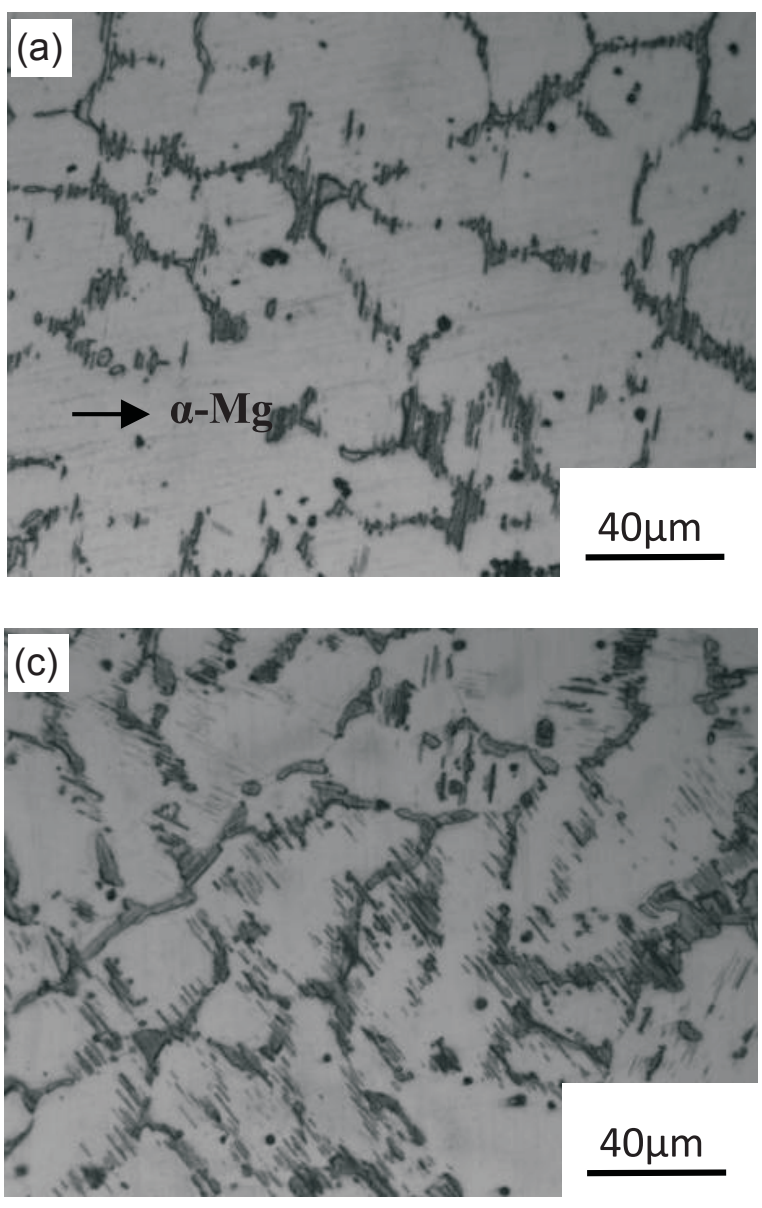

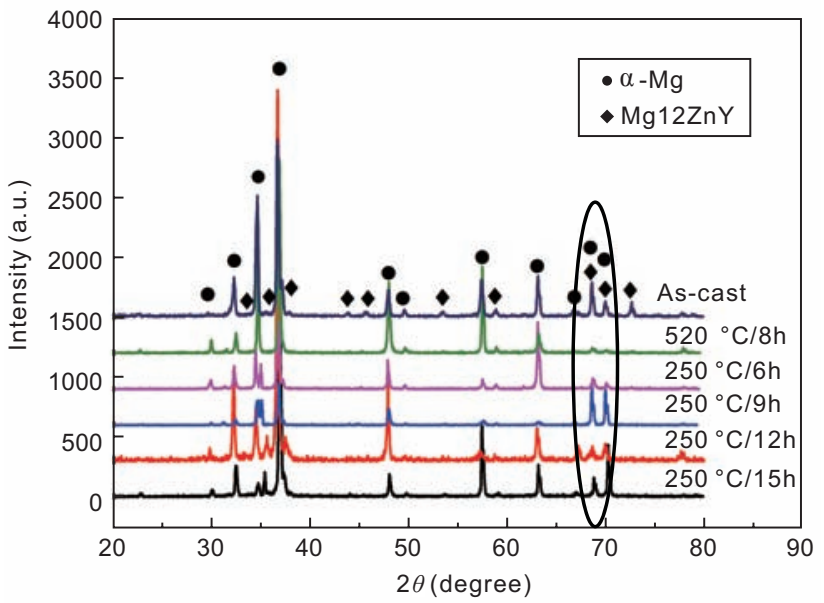

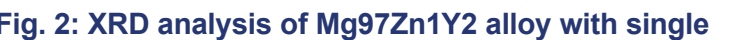

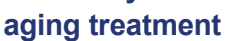

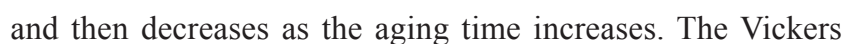

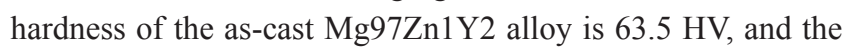

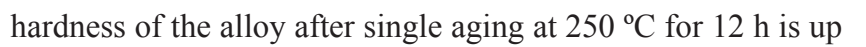

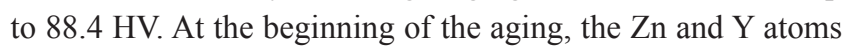

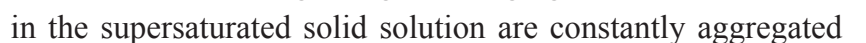

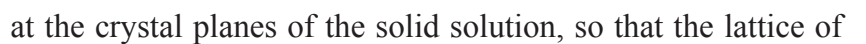

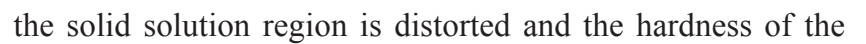
alloy increases. With an increase of the aging time, $\mathrm{Zn}$ and $\mathrm{Y}$

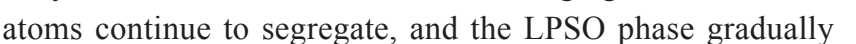
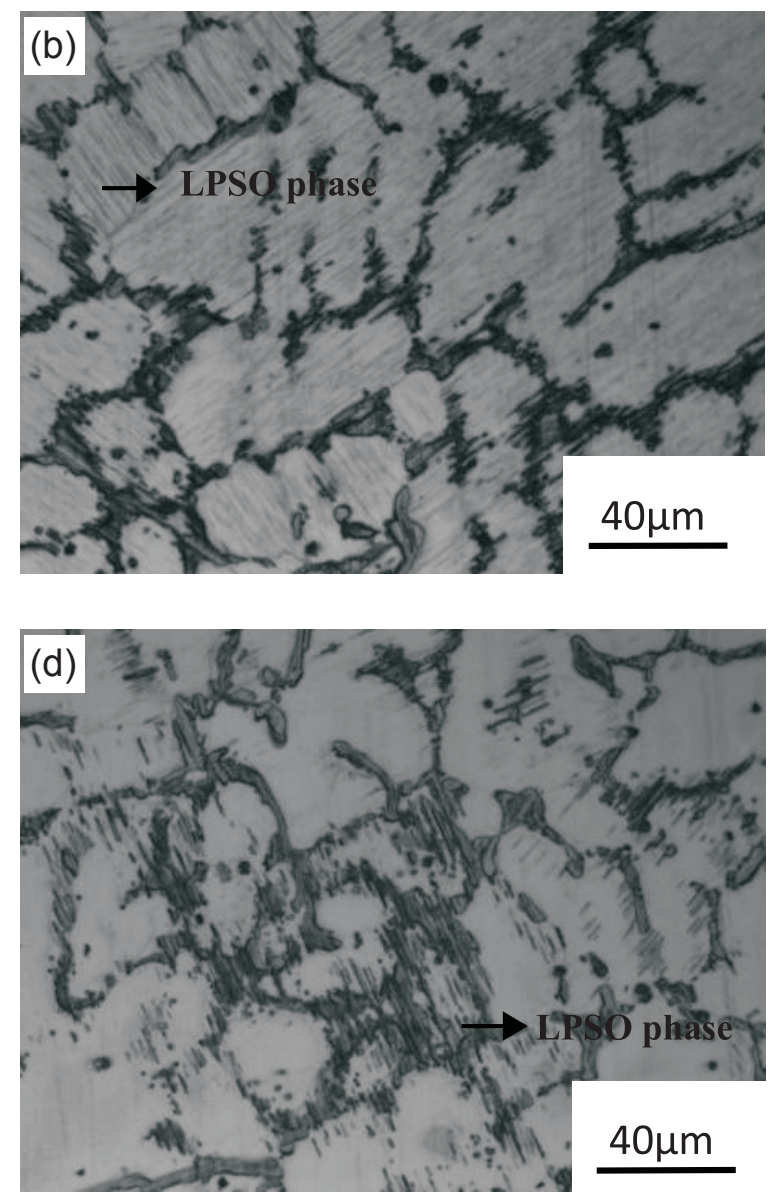

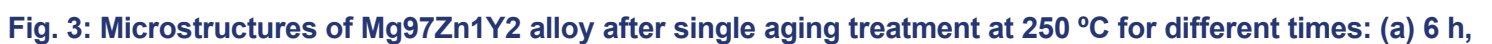

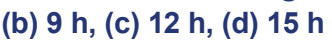




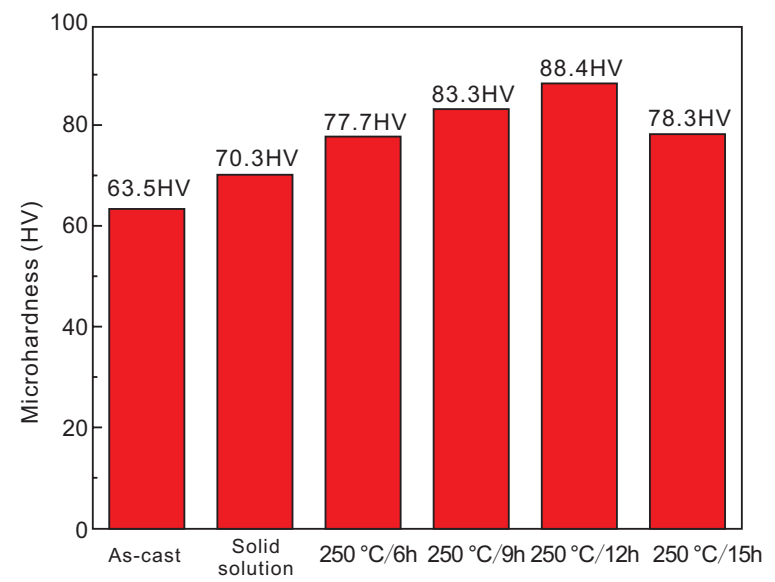

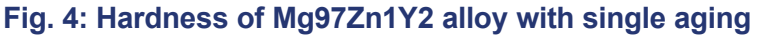
매밈

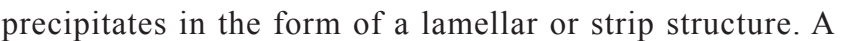

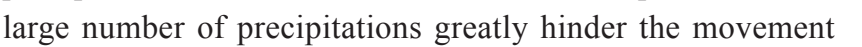

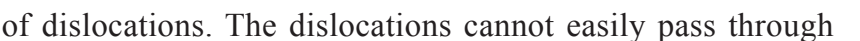

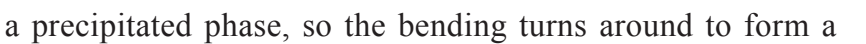

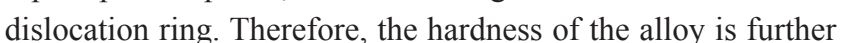

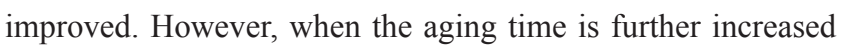

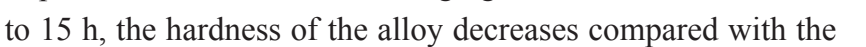

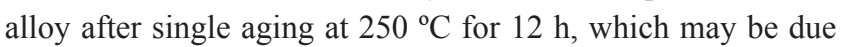

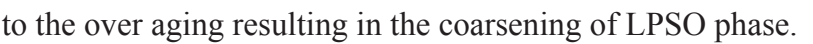

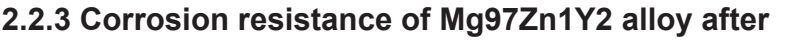

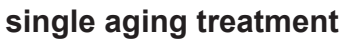

When immersed in $3.5 \% \mathrm{NaCl}$ solution, the self-corrosion

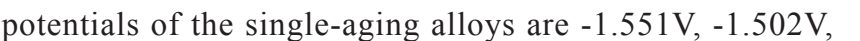

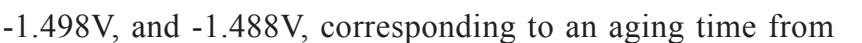

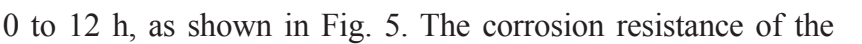

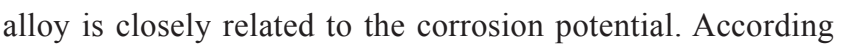

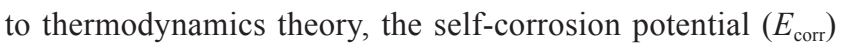

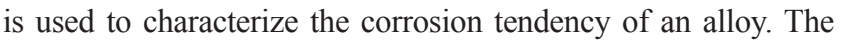

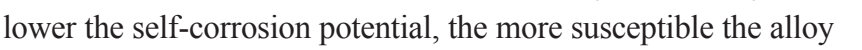

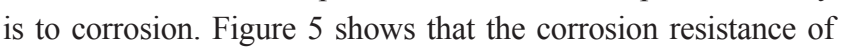

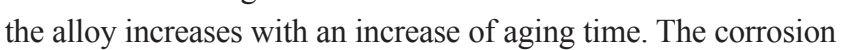

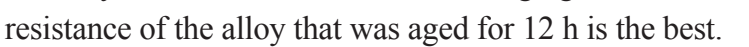

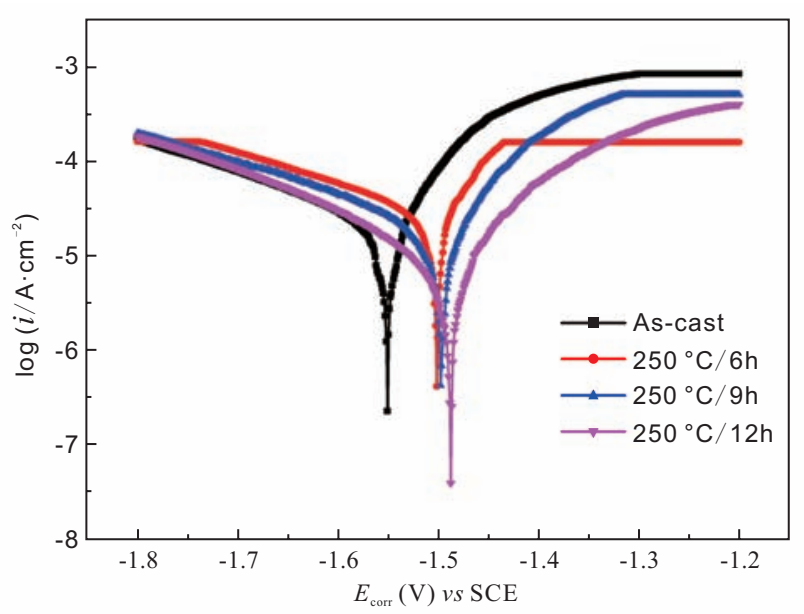

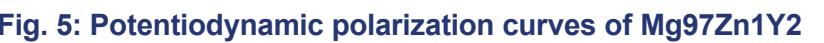

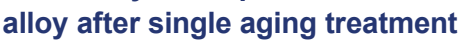

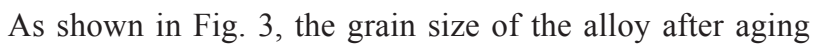

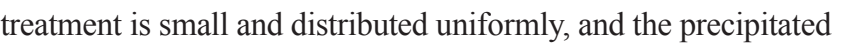

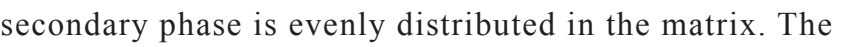

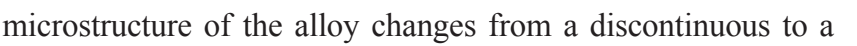

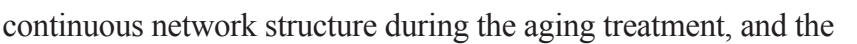

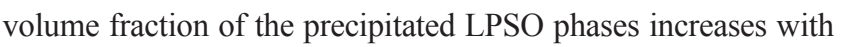

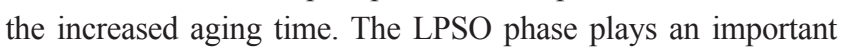

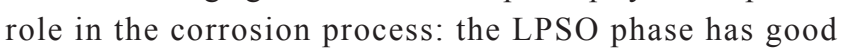

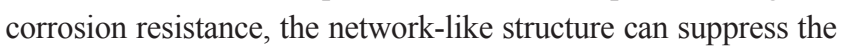

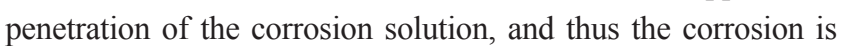

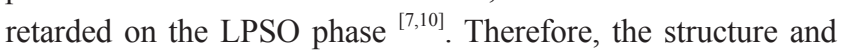

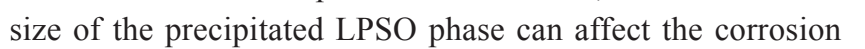

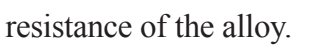

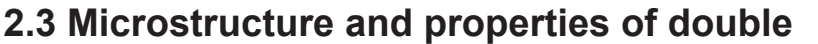

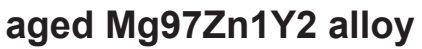

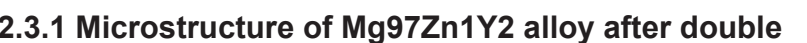

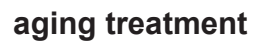

In the double-aging treatment, the specimens were firstly aged

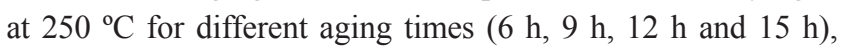

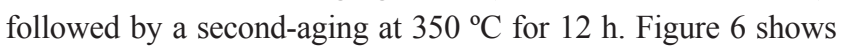

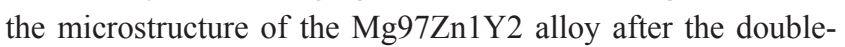
aging treatment. The dispersed and fine secondary phase further

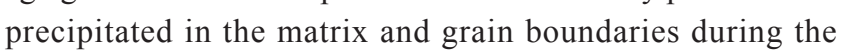

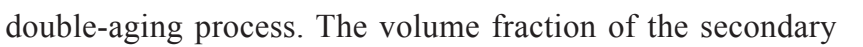

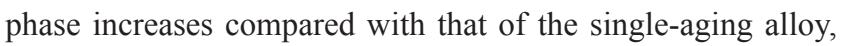

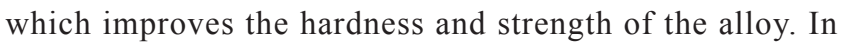
ए ए

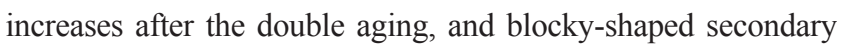

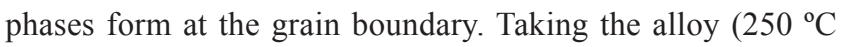

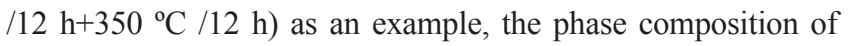
the alloy does not change. It is still composed of $\alpha-\mathrm{Mg}$ and

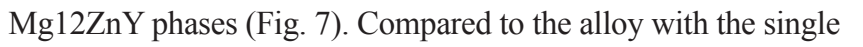

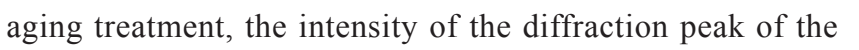
$\alpha-\mathrm{Mg}$ phase is weakened. The Mg12ZnY phase diffraction peak

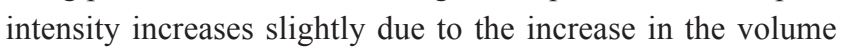

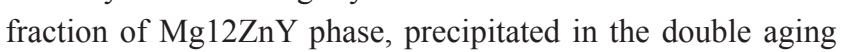
पाणाए

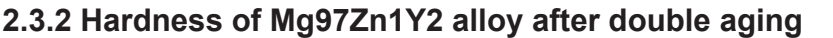 $\square \square \square \square \square \square \square$}

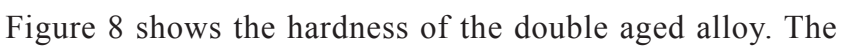

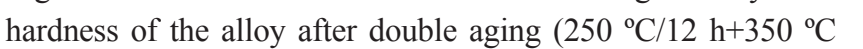

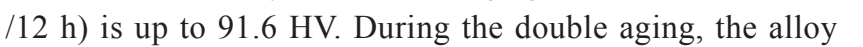

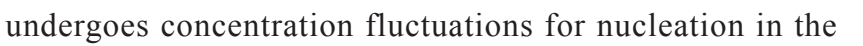

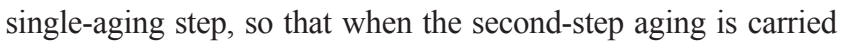

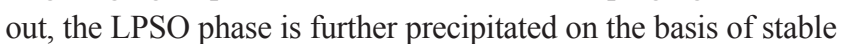
nuclei. The dispersed fine LPSO phase distributed in the matrix

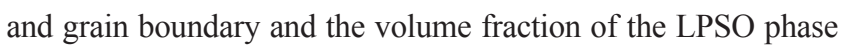

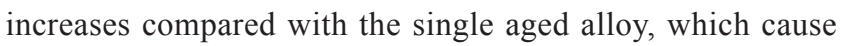

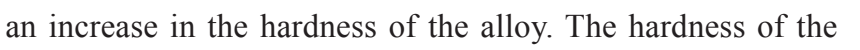

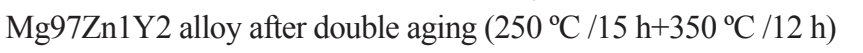

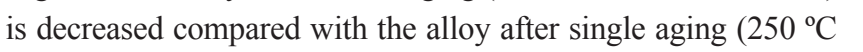

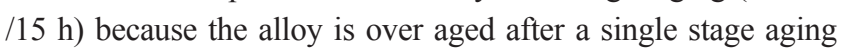

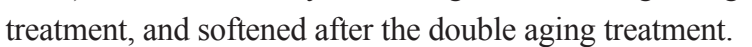



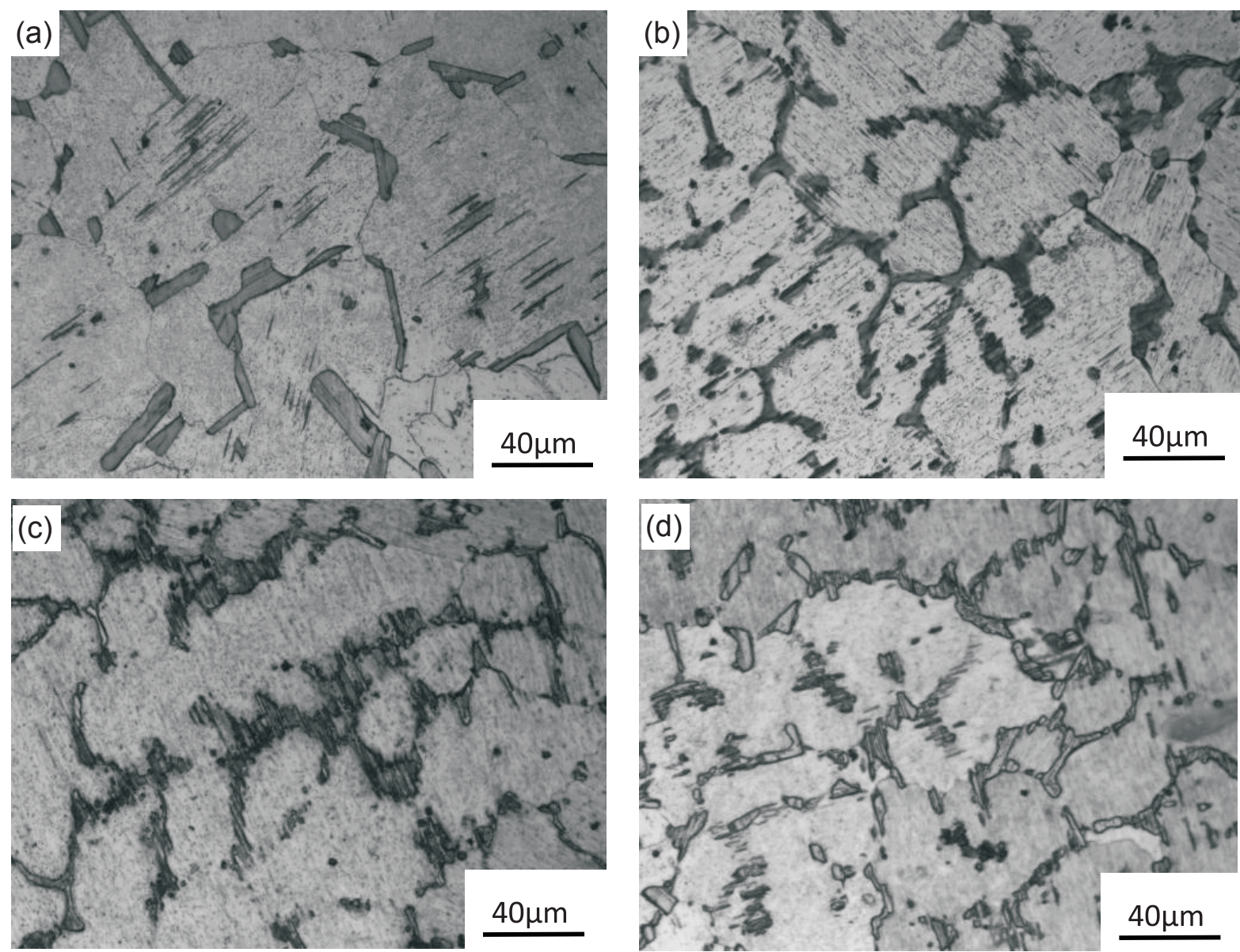

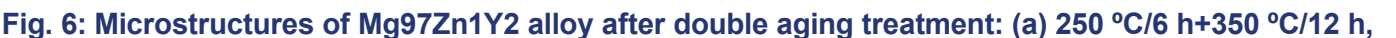

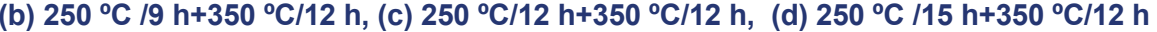

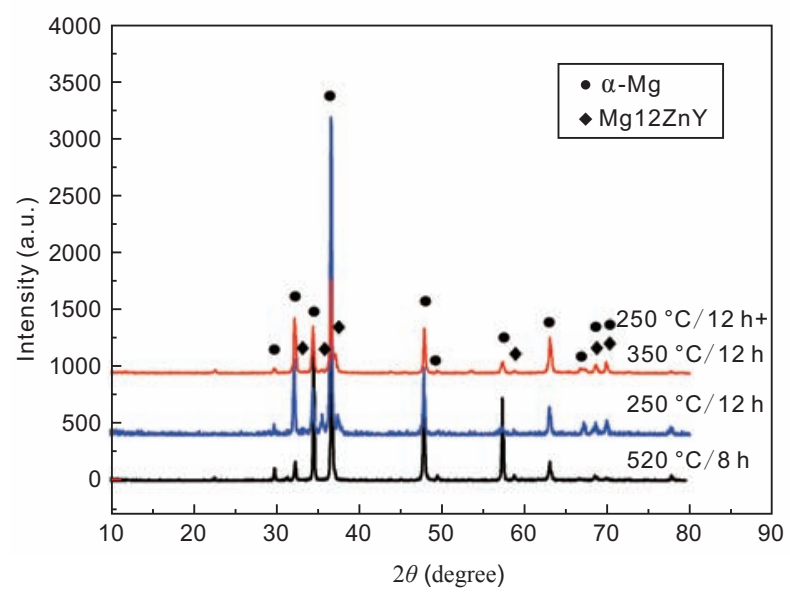

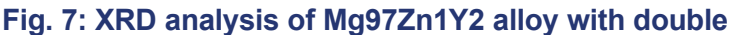

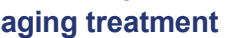

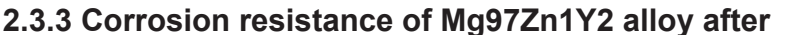

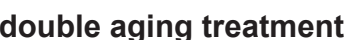

When immersed in $3.5 \% \mathrm{NaCl}$ solution, the self-corrosion

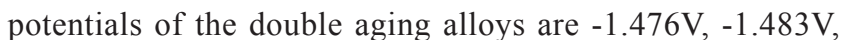
$-1.511 \mathrm{~V}$, and $-1.404 \mathrm{~V}$, corresponding to the first-step aging

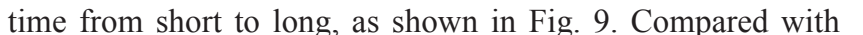

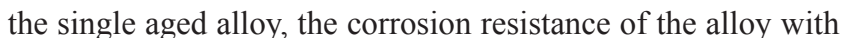

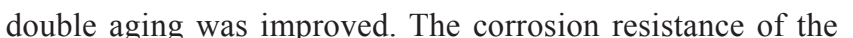
alloy $\left(250{ }^{\circ} \mathrm{C} / 15 \mathrm{~h}+350{ }^{\circ} \mathrm{C} / 12 \mathrm{~h}\right)$ is the best. When the alloy

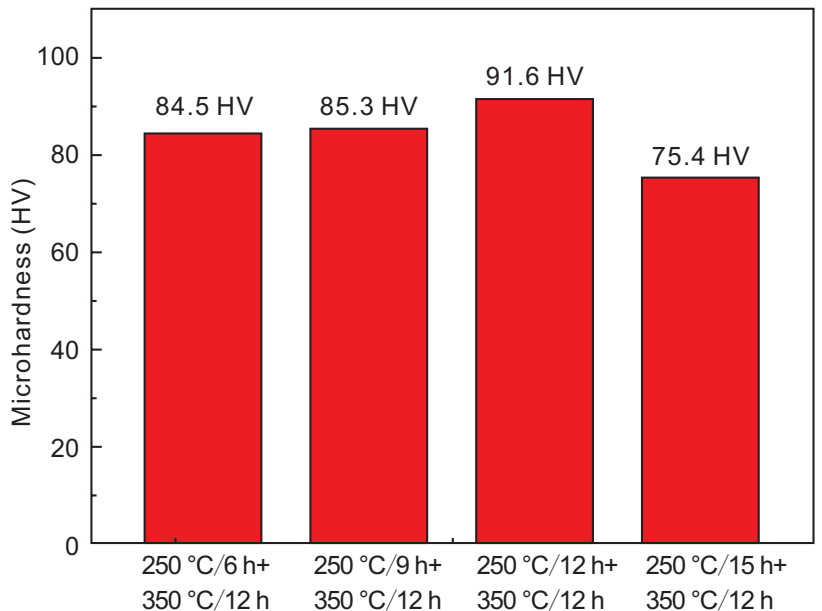

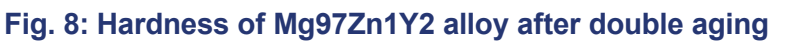

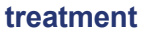

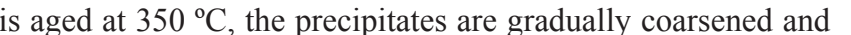

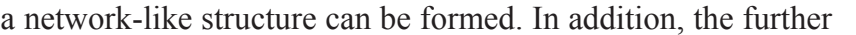

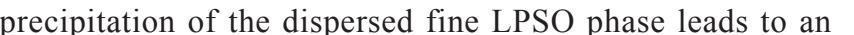

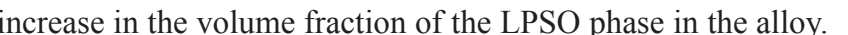
Many fine LPSO phases are distributed in the matrix, so that

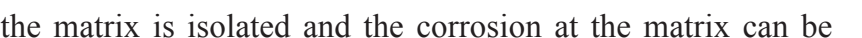

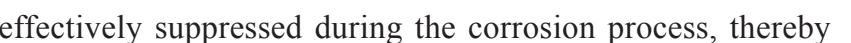

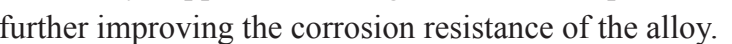




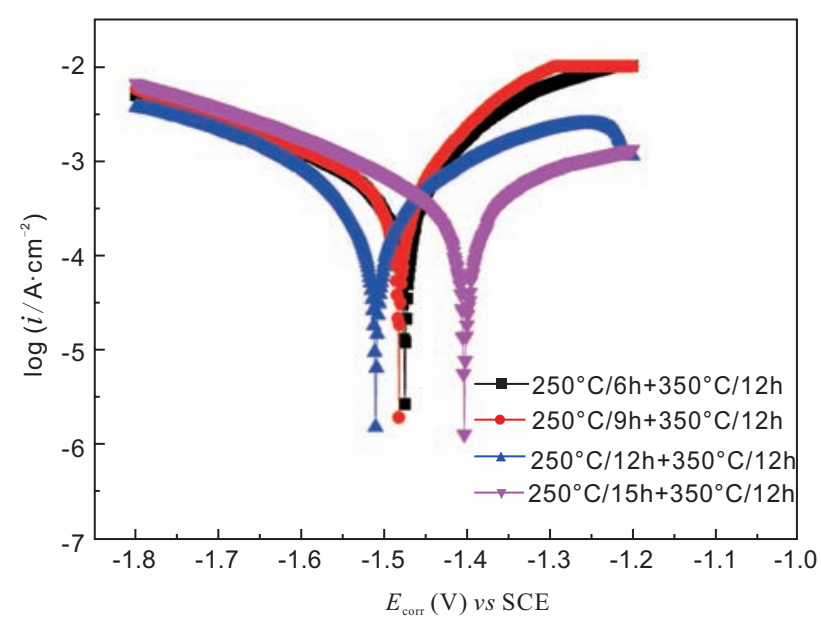

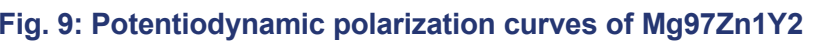

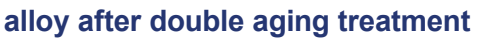

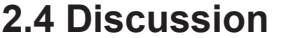

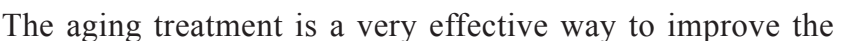

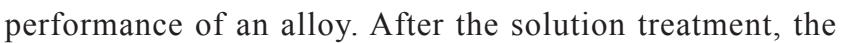

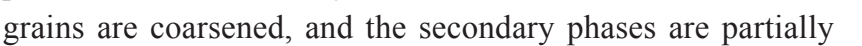
dissolved into the alloy. Because the Y-rich phase is difficult

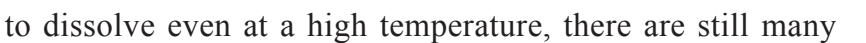

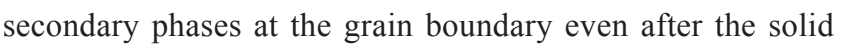

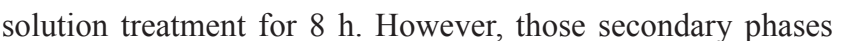

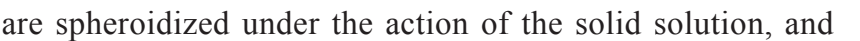

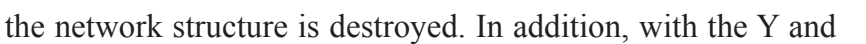

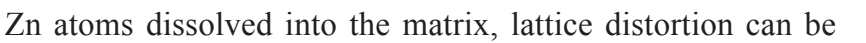
$\square \Pi\|\| \square \square$

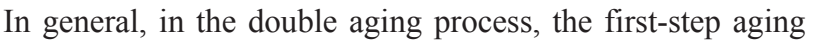

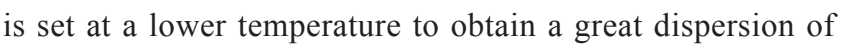

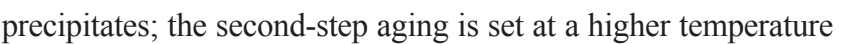

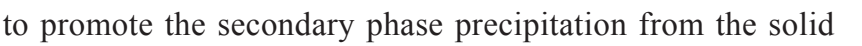

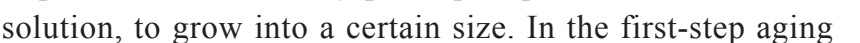

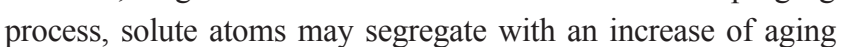

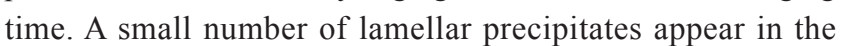

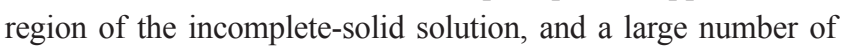

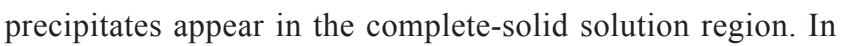

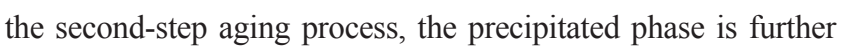

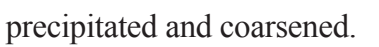

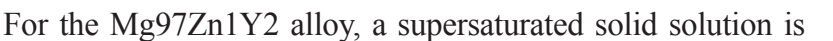

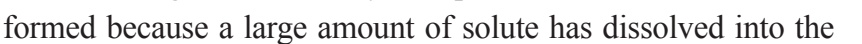

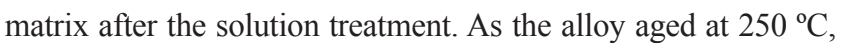

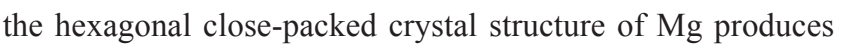

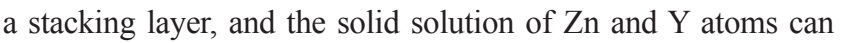

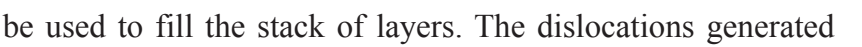

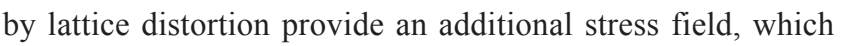

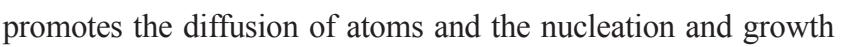
of the LPSO phase. When the aging time is short, most of the

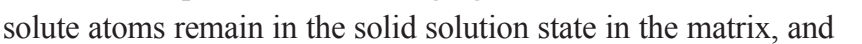

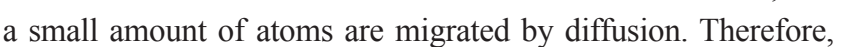

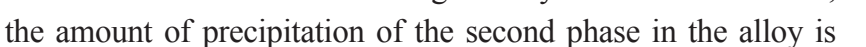

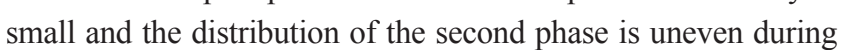

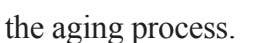

When the alloys were aged at $350^{\circ} \mathrm{C}$, the $\mathrm{Y}$ and $\mathrm{Zn}$ atoms that are dissolved in the matrix are precipitated again to fill the staggered layer, to form the nucleation of a fine LPSO phase.

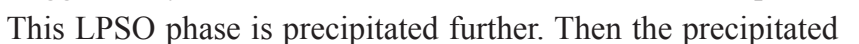

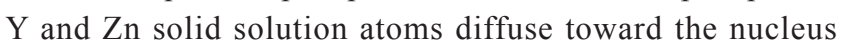

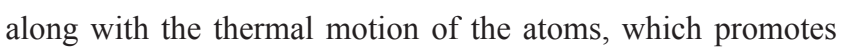

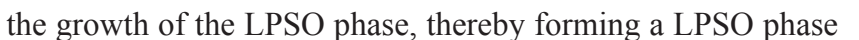

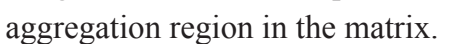

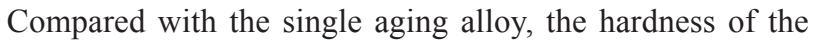

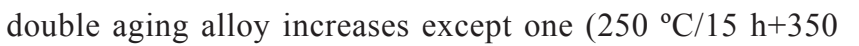

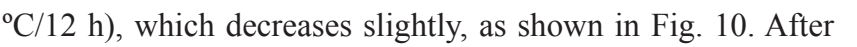

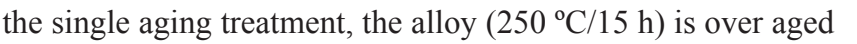

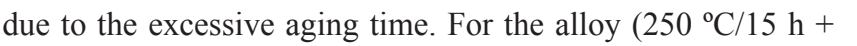

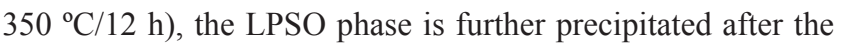

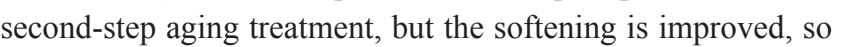

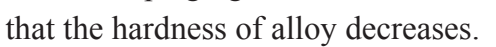

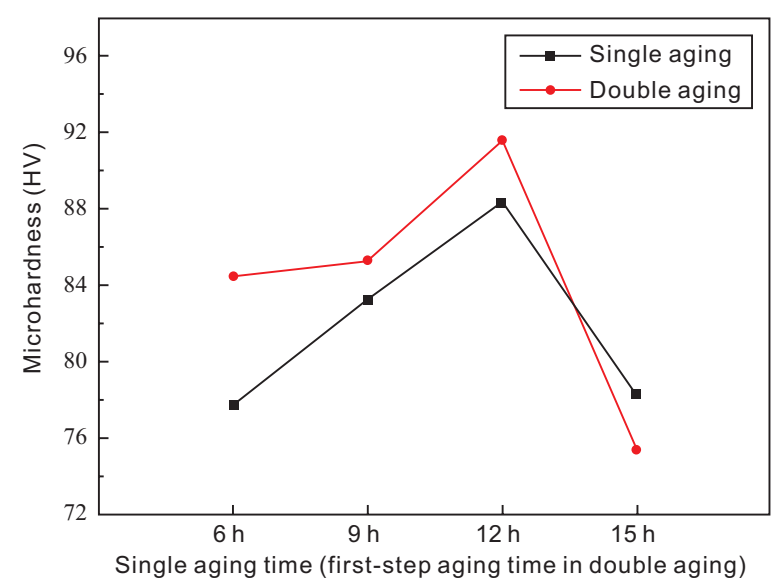

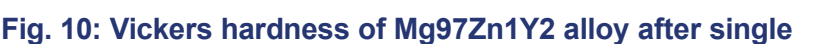
$\square$
0

\section{Conclusions}

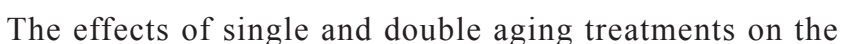

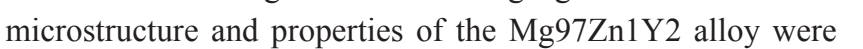

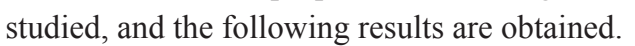

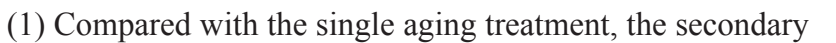

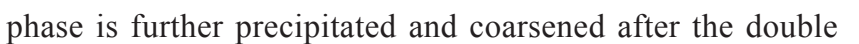
एवापापापाप

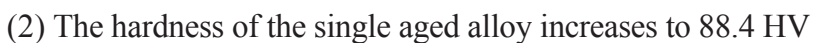

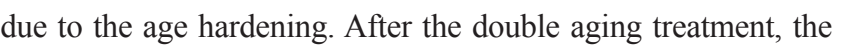

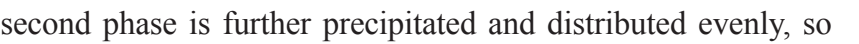

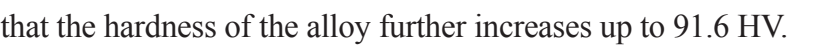

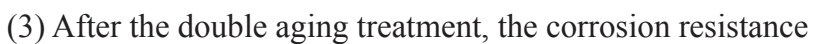

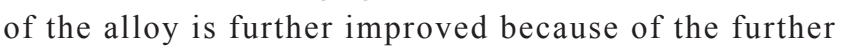

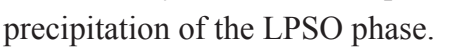

\section{References}

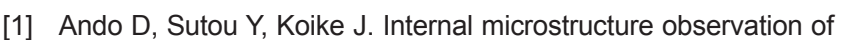

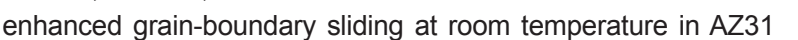

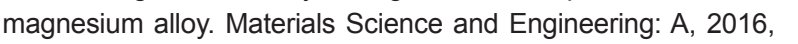

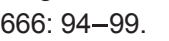

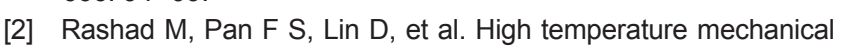

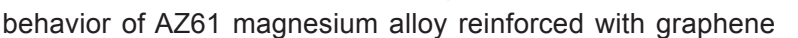

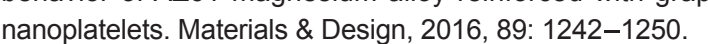




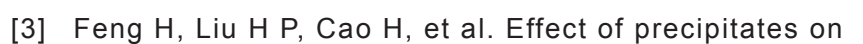
mechanical and damping properties of $\mathrm{Mg}-\mathrm{Zn}-\mathrm{Y}-\mathrm{Nd}$ alloys.

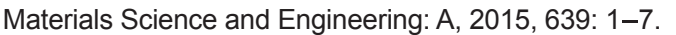

[4] Nagaraj M Chelliah, Ram Kumar, Harpreet Singh, et al.

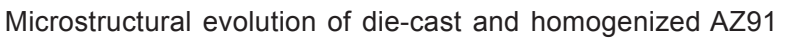

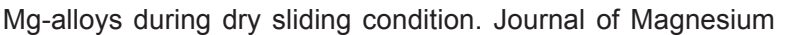

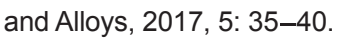

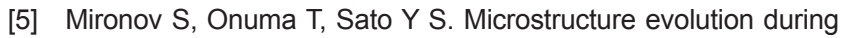

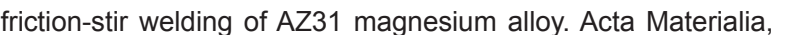

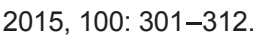

प

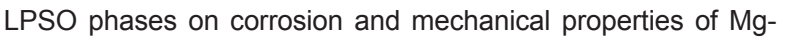

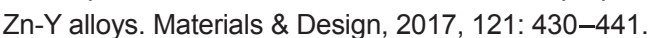

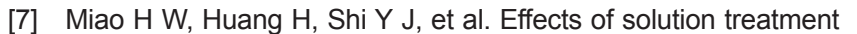

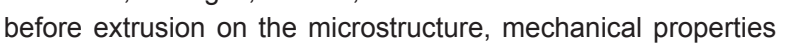
and corrosion of Mg-Zn-Gd alloy in vitro. Corrosion Science,

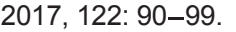

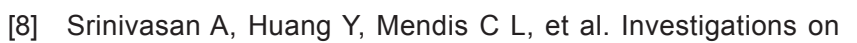

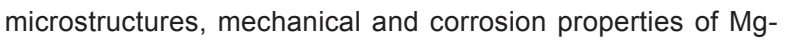
Gd-Zn alloys. Materials Science and Engineering: A, 2014, 595:

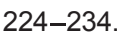

[9] Wang S D, Xu D K, Chen X B, et al. Effect of heat treatment on (1)

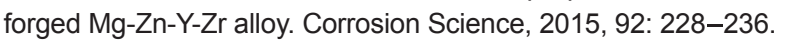

[10] Mousavi Anijdan S H, Kang D, Singh N, et al. Precipitation

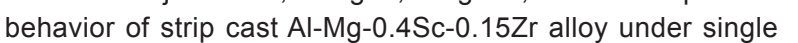

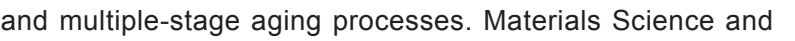

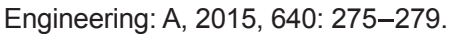

[11] Santhosh R, Geetha M, Saxena V K, et al. Studies on single and duplex aging of metastable beta titanium alloy Ti-15V-3Cr-3Al-

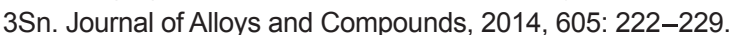

प

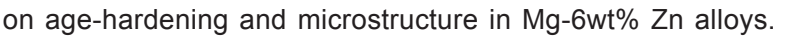

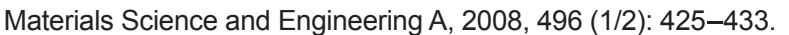

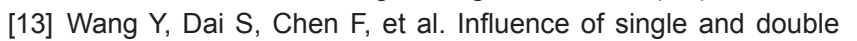

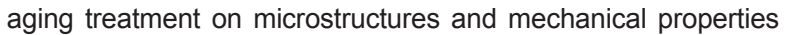
of cold rolled Ti-30Nb-5Ta-6Zr alloy. Materials Science and

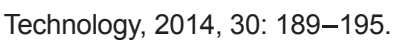

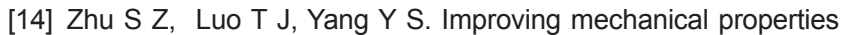

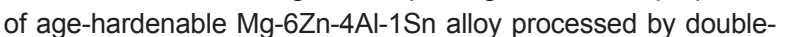

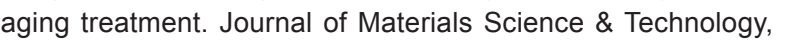

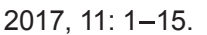

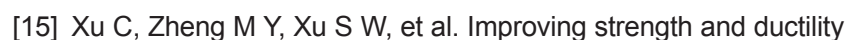
of Mg-Gd-Y-Zn-Zr alloy simultaneously via extrusion, hot rolling

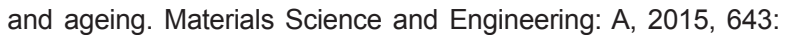

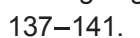

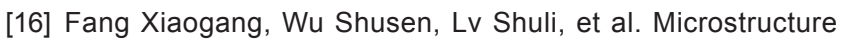

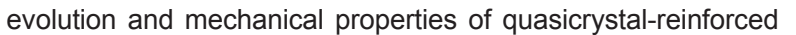

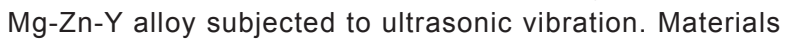

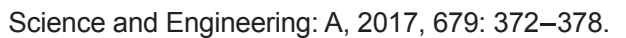

(I)

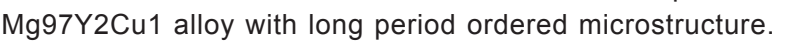

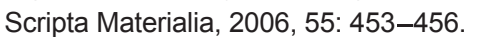

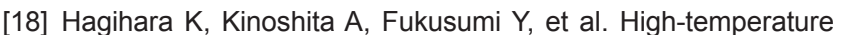

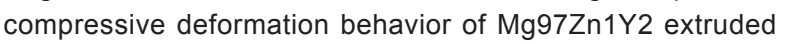

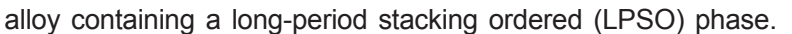

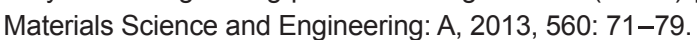

प

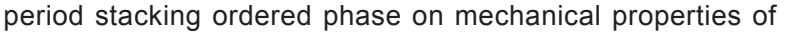

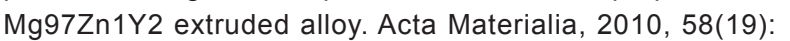
$\square[\square] \square \square[\square]$

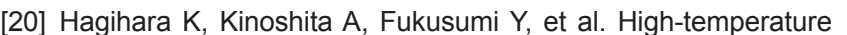

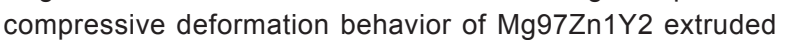
प

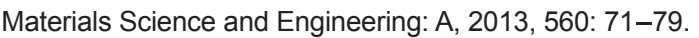

[21] Jin Q Q, Shao X H, Hu X B, et al. New polytypes of long-period

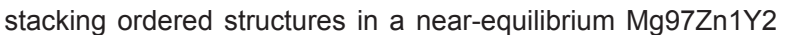

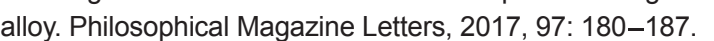

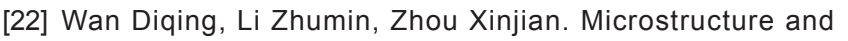

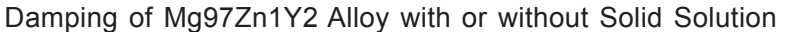

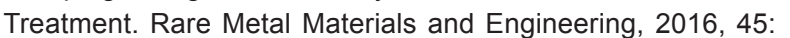

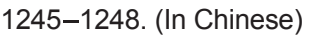

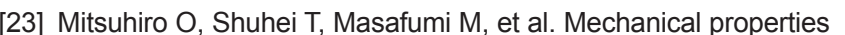

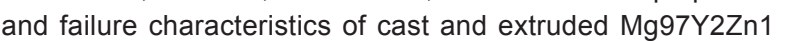

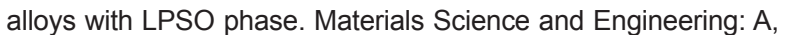

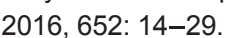

[24] Zhu Y M, Morton A J, Nie J F. The $18 \mathrm{R}$ and $14 \mathrm{H}$ long-period

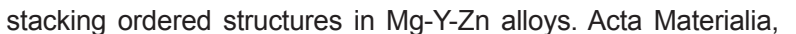

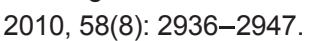

[25] Gröbner J, Kozlov A, Fang X Y, et al. Phase equilibria and

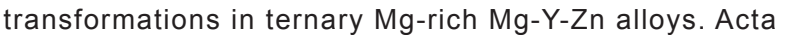

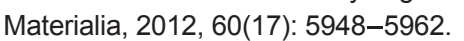

This research was financially supported by the National Natural Science Foundation of China (Grant No. 51665012) and the Jiangxi Province Science Foundation for Outstanding Scholarship (Grant Nos. 20171BCB23061, 2018ACB21020). 